\title{
MID-AIR RETRIEVAL TECHNOLOGY FOR RETURNING OF REUSABLE LAUNCH VEHICLES' BOOSTERS
}

\section{S. V. Antonenko and S. A. Belavskiy}

The multilateral analysis of reusable launch vehicles (RLV) has been carried out by the authors' team within 8 years. The studies are based on the world experience and also on the large practical experience of Khrunichev Space Center in designing, production, and operation of aerospacecraft (incuding reentry one). The analysis results are monosemantic and are the following: The only one feasible principle for the nearest future is a mid-air retrieval (MAR), which will permit potentially the creation of the effective RLV. For practical realization of the results obtained, the authors in cooperation with M. L. Mil's Moscow Helicopter Plant (MHP) and "Parachute Design" Scientific Institute have developed the launch vehicles' booster MAR technology (including the structure and principles of main elements formation). The general conclusions of the mar technology are the following: $(i)$ it can be realized with a minimal technical risk at the earliest time (2-3 years); ( $i i)$ it can be applied to the existing expendable launch vehicles (ELV) and can be easily adapted to different launch vehicles; (iii) it can be demonstrated at minimal costs and time; and $(i \nu)$ it permits the creation of the most economically effective RLV (budget savings will be up to $30 \%$ and in case of using a special operation technology, the savings can attain $41.5 \%$ ).

\section{TECHNOLOGY REALIZATION}

\subsection{Existing Mid-Air Retrieval Technologies}

The MAR by airplanes or helicopters is widely used in the world since 1960s. There were more than 2 million MAR operations till today [1].

The following examples can be given among others:

- Rescue of the containers of Artificial Earth Satellites ("Discovery" and "Genesis," Fig. 1a), geophysical rockets and spacecraft ("Genesis," Fig. 1b); 


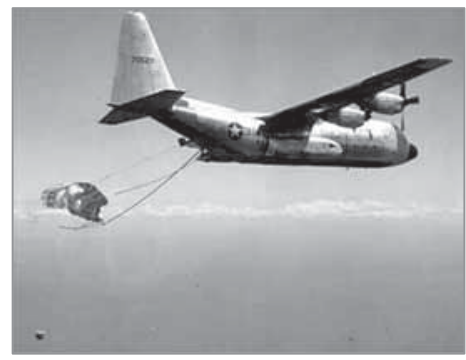

(a)

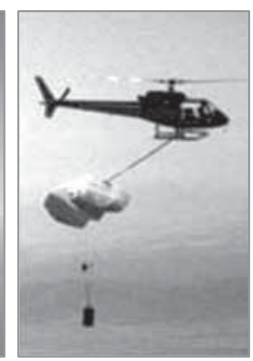

(b)

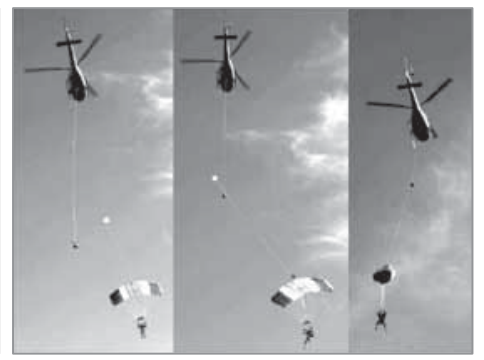

(c)

Figure 1 Examples of object MAR

- Rescue of remote piloted apparatus and airplane models;

- MAR of cargoes and people from the ground and water surfaces (parachutists, etc. (Fig. 1c)).

The reliability of the first MAR systems (1960s-1970s) was 75\%-88\% [2] and it is approaching $100 \%$ today [3].

The space launch vehicle boosters have dimensions which do not allow pulling them into the cargo compartment of an airplane or helicopter. It is therefore necessary to transport them using the external suspension. However, the airplane, in contrast to helicopter, is not capable of hovering above airfield for cargo stacking. Thus, an intermediate transfer of cargo from airplane to helicopter or on a loop stretched highly above the ground is required. For this reason, the airplane is not considered in the present paper.

The cargo MAR capabilities are determined, on the one hand, by the relationship of the cargo captured and the maximum helicopter takeoff weight and by the parachute system providing the MAR at this cargo weight, on the other hand.

The load-carrying capabilities of Mi-26 helicopter allow capturing the cargo with weight of about $10 \mathrm{t}$ without helicopter modernization and about $20 \mathrm{t}$ with helicopter modernization (as per MHP).

On the contrary, the up-to-date potential of the MAR parachutes does not allow realizing the helicopter capabilities, limiting the saved cargo weight by about 2 t.

As is known, the MAR parachute is used for heavy cargoes to decrease the main parachute weight and the dimensions of the element, for which the MAR is carried out. However, the main parachute area is also increased with the cargo weight. The MAR parachute weight and the cross-section area of the link (wire ropes) with the main parachute are also increased to ensure the strength. Simultaneously, for the MAR parachute removal from the vortical trace of the 


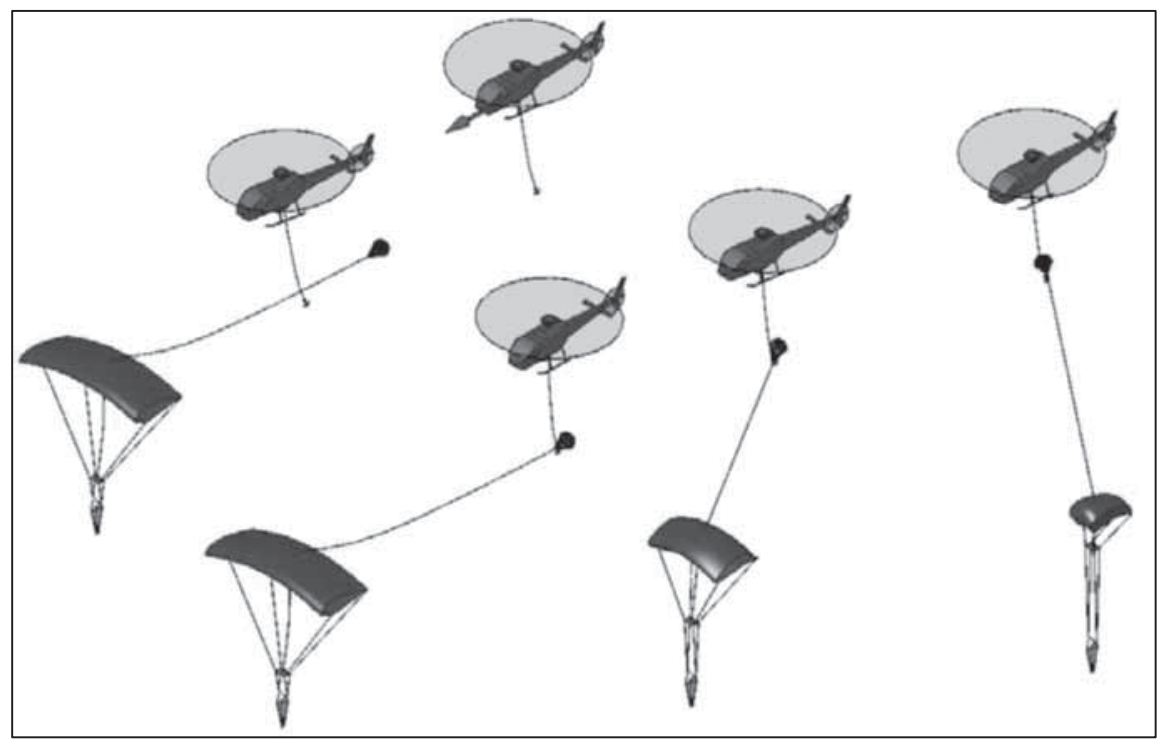

Figure 2 3GMAR

main parachute, it is necessary to extend the link (wire rope) between them. Therefore, it is necessary to increase again a parachute area for maintaining the same weight by the MAR parachute. As a result, the weight, which is to be maintained by the MAR parachute with increasing the cargo weight, increases faster than the MAR parachute lift. For this reason, the MAR parachute becomes unacceptably large, it is swung or even folded.

At the end of 2002, Lockheed Martin Space Systems Company and Vertigo undertook a sudy to extend the MAR system capabilities for cargoes of 10$13 \mathrm{t}$ [4]. It is supposed that the system developed by them (3GMAR) will be used for reentry of the "Atlas-5" launch vehicle booster tail comparment.

The essence of 3GMAR system (Fig. 2) consists in the use of parafoil as a main parachute. The MAR parachute is towed behind the main parachute. The helicopter catches up the parafoil from the wake side and catches on the wire rope by a hook (it is suspended under the helicopter). Special measures are also used to reduce MAR overloads due to the energy expenses for friction about slings and parafoil folging.

The 3GMAR advantage is a reduction of overloads and relative velocity at MAR. The large towage velocity of the MAR parachute provides its large stability. The MAR is carried out for wire rope.

However, the serious drawback of 3GMAR is high cost of parafoils for cargoes of large weight. The reason is complexity of maintenance of large parafoil deployment. Besides, a control system of parafoil flight direction is needed to 
avoid chaotic changes of flight direction during MAR. Moreover, parafoils should be developed for different ranges of cargo weight (note that in the multicanopy landing force systems adopted in the arms, it is attained by varying a number of canopies). These drawbacks will limit wide application of 3GMAR, especially for military purposes.

\subsection{Supposed MAR Technology}

The authors offer an "object capture methods" virtually avoiding restrictions on a captured object weight. The restrictions will be connected only with the capturing capabilities of helicopter or airplane (see [5], the USA patent application has been disposed). Replacement of the MAR parachute by a rotor avoids all problems relevant to parafoil. With the rotor engine, it is possible to supply necessary thrust. Besides, it has the gyroscopic properties of untwisted propeller which stabilizes rotor position.

Based on this invention, the launch vehicle booster MAR technology has been developed (Fig. 3).

As compared with 3GMAR, the advantage is a possibility to develop a system using existing parachutes, which have a considerably lower cost, high reliability,

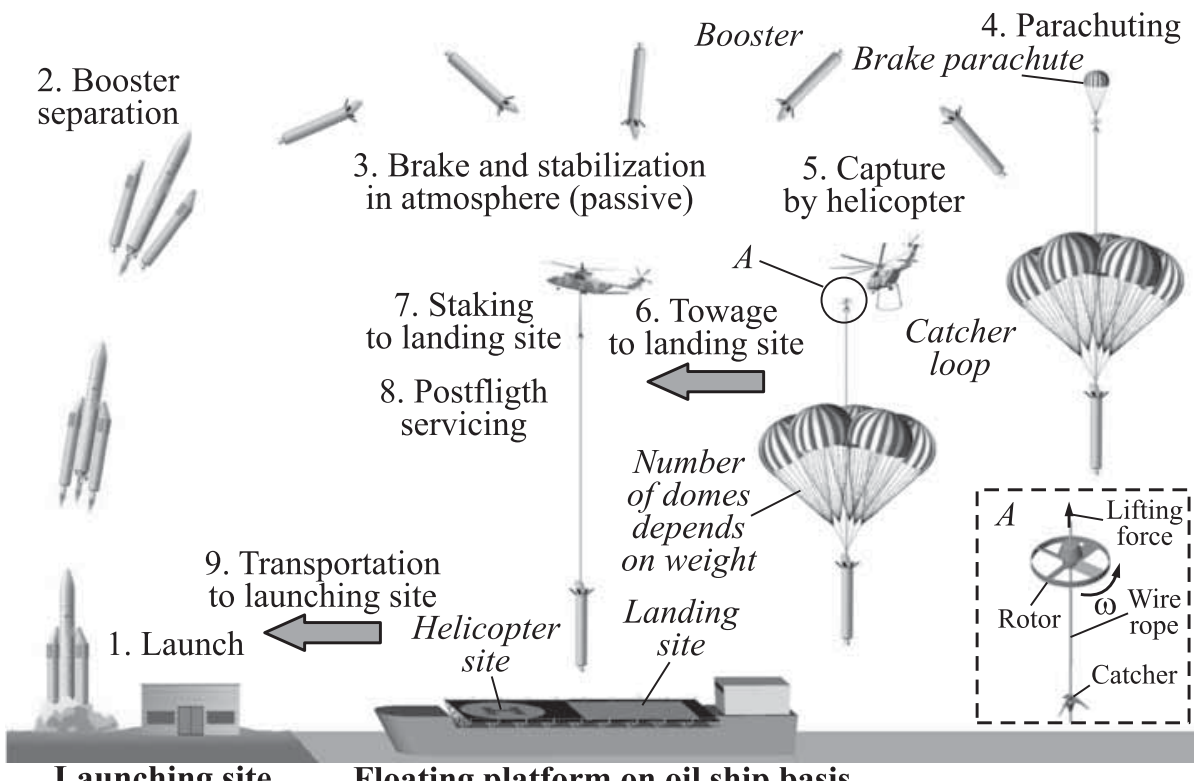

Launching site

Floating platform on oil ship basis

Figure 3 Schematic of system functioning on an example of "Ariane-5" launch vehicle 
and large experience in the army. The multicanopy parachute MAR system may be easily adapted for the object weight (in wide range) by changing the number of canopies. The absence of canopy gliding may lead to a large relative velocity of helicopter and cargo but it simplifies approaching the target and decreases the danger of changing the gliding direction simultaneously.

In the case of MAR of several boosters, in the MAR area, the boosters will be at a distance from each other as they are pushed away from different sides at separation from launch vehicle. Besides, for successive withdrawals of boosters, the parachute systems may be adapted for different injection altitudes.

The insert in Fig. 3 shows the principal scheme of the rotor.

\section{UNIVERSALITY AND ADAPTABILITY}

The MAR technology may be adapted to reenter the launch vehicle boosters of almost any type. If the booster weight exceeds the MAR capability, the booster may be partitioned (for example, by pyro devices), suitable for rescue. As the most expensive part of the booster is engine, so only the tail part of the booster may be rescued.

In order to ensure the reentry of the booster (Fig. 4), its front compartment is supplied with MAR equipment. The parachute system that is offered is a multicanopy modification of the "Ariane-5" booster parachute system (developed by "Parachute Design" Scientific Institute). The number of canopies may be varied depending on the object rescue weight.

For protecting the booster against thermal factors, the additional thermal protection cover can be installed. The protective covers can be installed also on the engine nozzle. At present, a more advanced design solution minimizing engine modification is under development.

For reducing the impact areas and loads on the booster, the stabilization blinds can be installed. Such solution excludes a jet control system for descending (often applying toxic components).

The weights shown in Fig. 4 are related to the "Angara" launch vehicle boosters as per results of design studies and aerodynamic and thermal calculations with account for parameters deviations at reentry into atmosphere. The parachute system weight is determined by experts of "Parachute Design" Scientific Institute.

In general, all modifications are local and exert minimum influence on the launch vehicle structure, launching site, and flight performance (see, for example, Table 1).

Besides, being applicable to boosters, the MAR technology can be used for landing of manned spacecraft (e.g., for the spacecraft of "Soyuz" type). In case of MAR, comfortable overloads and fast delivery will be ensured. Otherwise, the 


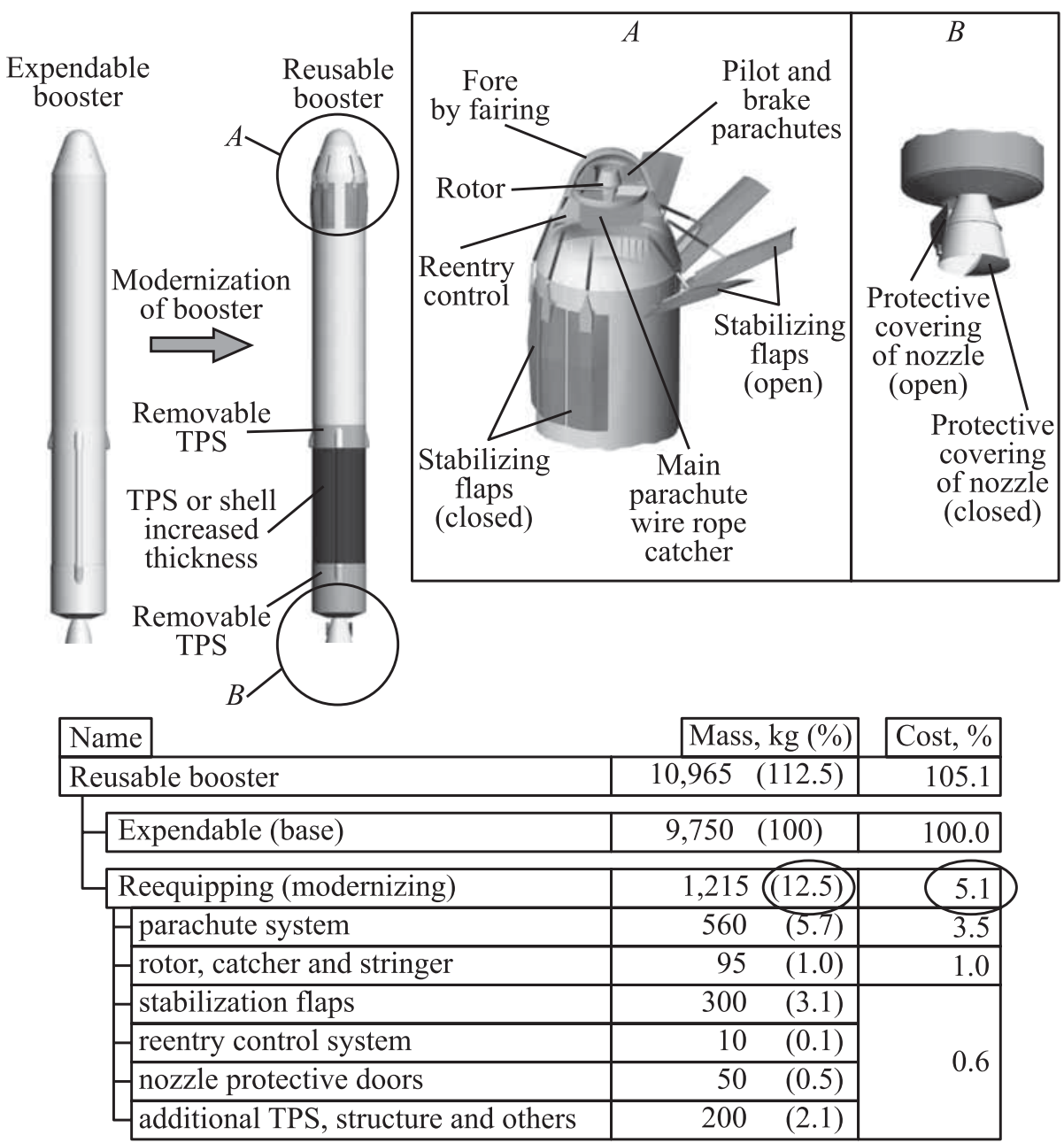

Figure 4 Transformation of expendable booster families of "Angara" launch vehicle into reusable ones (TPS - Throttle Position Sensor)

Table 1 Family of "Angara" launch vehicle with MAR boosters of first stage

\begin{tabular}{lccc}
\hline Launch vehicle & $\begin{array}{c}\text { PL into LEO } \\
\text { (Plesetck), } \\
\mathrm{kg}\end{array}$ & $\begin{array}{c}\text { Decrease of mass } \\
\text { of injected PL, } \\
\%\end{array}$ & $\begin{array}{c}\text { Decrease } \\
\text { of launch net cost, } \\
\%\end{array}$ \\
\hline Angara-1.2 & 3,500 & 5.4 & 21 \\
Angara-A3 & 14,000 & 4.1 & 38 \\
Angara-A5 & 23,750 & 3.1 & 30.4 \\
\hline
\end{tabular}


spacecraft will land using the standard system of "soft landing." The MAR system installation will not worsen weight characteristics because the requirements to the engines of soft landing will be reduced (in this case, it will be a reserve system).

\section{DEMONSTRATION AND TESTING}

The booster MAR technology can be readily demonstrated at a minimal cost on the example of MAR of cargo with a weight of 5,000 kg. The P-7 parachute platform (its cost is approximately $\$ 100,000$ and its usage resource is 15 times) can be used for this purpose. The platform is supplied with a special unit providing all necessary means for MAR. This unit replaces one of 5 main parachutes of the standard platform (Fig. 5). In this case, all conditions are met which are close to the real booster MAR.

Such modification of P-7 platform can be included into the standard operation and can be used for delivery of different cargo in the future.

\section{ECONOMIC EFFECTIVENESS}

\subsection{Existing Technology Problems}

In this section, the existing reentry technology problems are analyzed using the diagram shown in Fig. 6. This diagram was prepared by the authors based on the official database of the Khrunichev Space Center. The first column in the left shows the specific cost of payload injection by the heavy ELV like "Angara-A5" launch vehicle (Khrunichev's project). This cost is taken a baseline for further comparisons (i.e., 100\%).

The column in the diagram consists of several parts showing various cost components: the lower part is launch vehicle and PL adaptation, the medium part is the cost for launch maintenance and realization, and the upper part is the cost of launch vehicle manufacturing. For the further analyses, the cost of manufacturing is divided into the cost of launch vehicle first stage and its remaining part.

This ELV can be transformed to the reusable launch vehicle with the first stage reusable boosters (RBs). For ensuring reentry, these boosters are made using the Fly-Back technology, which is a most popular nowadays (for example, "Baikal" booster).

If all costs are the same, then, for example, at 100-multiple use, the RB cost for each specific launch will be $1 / 100$ from their full cost and $0.5 \%$ accordingly from the total launch cost price. Thus, one arrives at savings equal to $48.5 \%$ 


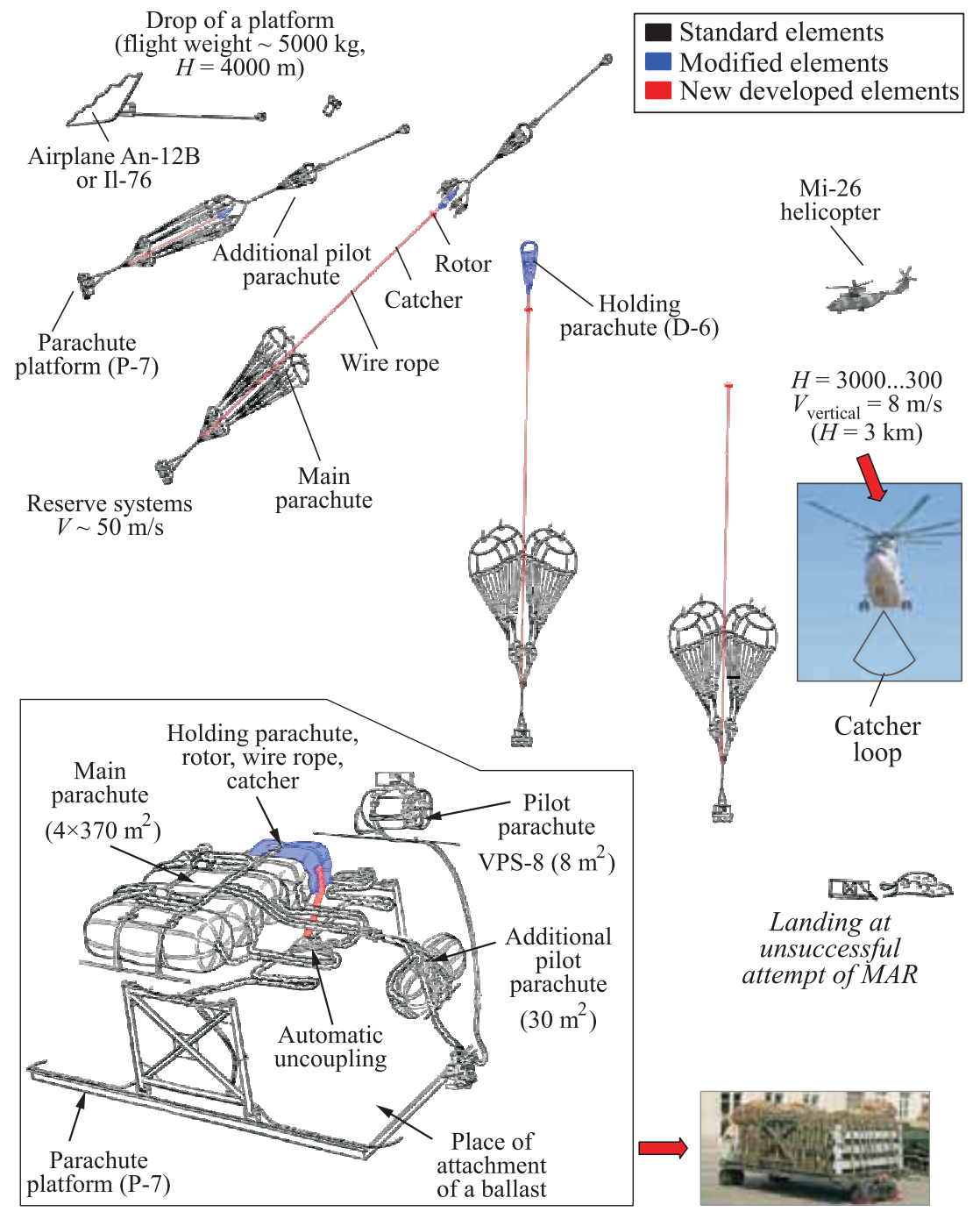

Figure 5 Application of P-7 parachute platform for demonstration of the new MAR technology. (Refer color plate, p. 488.)

(i.e., almost a factor of 2) in comparison with the ELV. This result is shown in the second column of the diagram of Fig. 6. It would be nice to put it into practice but it corresponds to an "ideal" case.

Now, one has to take into account all reasons increasing the cost of the RLV in comparison with the ideal case. These reasons are caused by different problems considered below. 


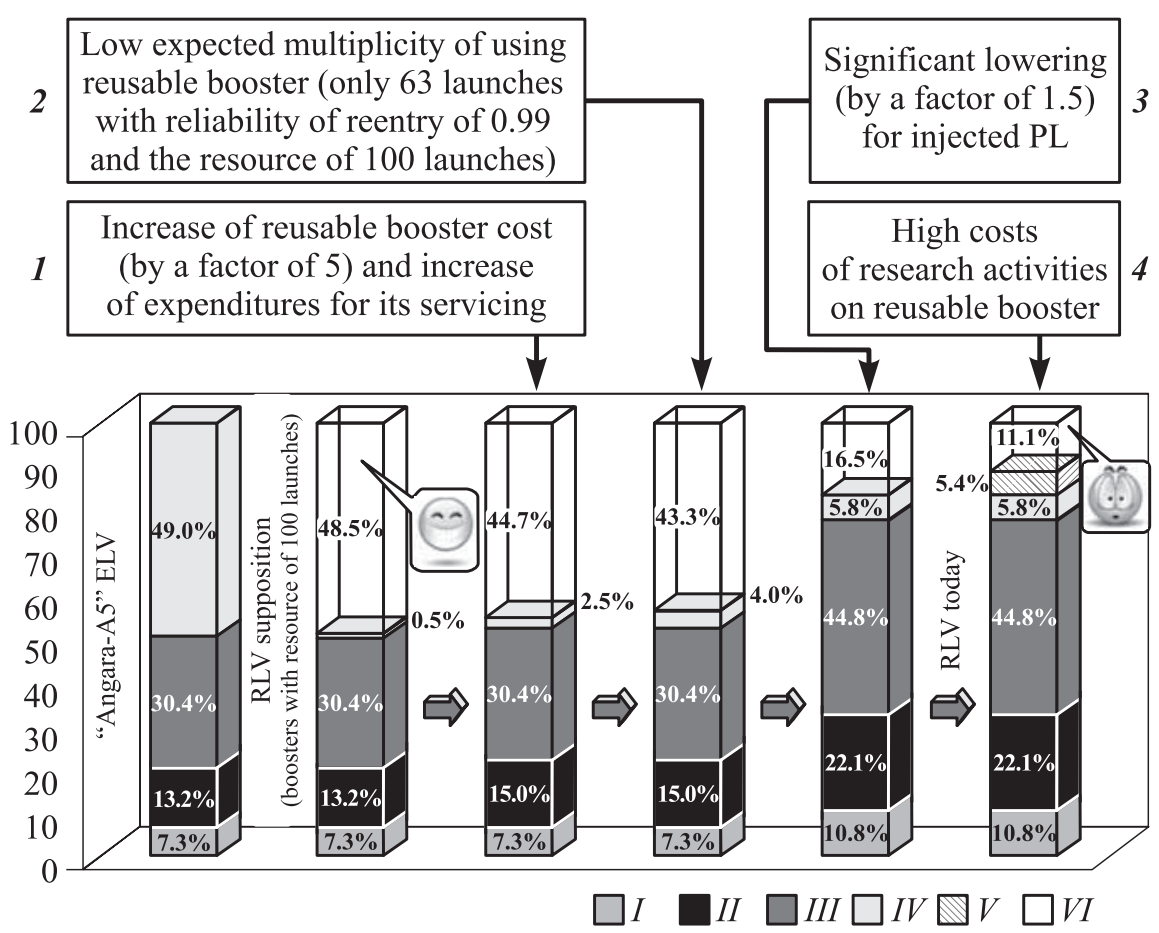

Figure 6 Problems of existing RLV projects (in terms of payload injection specific cost): I - adaptation with PL; II - reusable part of launch vehicle; III - launch support; $I V$ - amortization (125 launches); $V$ - expendable part of launch vehicle; and $V I$ - saving

First, take into account a problem, connected with the significant rise in the cost of $\mathrm{RB}$ as compared with the expendable one. This rise in the cost is about a factor of 5 , i.e., the cost share for each launch will become $2.5 \%$ instead of $0.5 \%$. Also, it is necessary to take into account the cost increase for the launch ensuring (due to additional operations), which will add $1.8 \%$ as the most optimistic evaluation.

Second, take into account a problem connected with the RB reentry probability. So, if one assumes the reentry probability equal to 0.98 according to the available experience of the launch vehicle operation, the average expected multiplicity of booster use will be only 42 launches instead of 100 (i.e., more than twice less). If the reentry probability is 0.99 , then the average expected multiplicity of booster use will be 63 launches.

Third, take into account a problem connected with a significant mass decrease of the payload to be injected. A "dry" mass increase for the RB made 
according to the Fly-Back technology will be about doubled as compared with the expendable analogs (additional jet engine with propellant and tanks, wing, unusual loads on launch vehicle, chassis, etc.). As a result, the payload will decrease by a factor of 1.5 for the launch vehicle of the reviewed class. To ensure the same cargo traffic, it will be necessary to make by a factor of 1.5 more launches which will result in increasing all costs by a factor of 1.5 per launch!

Fourth, take into account a problem, connected with the necessity to amortize the cost for the research and development work on the RB which are $675 \%$ (related to the baseline case) according to the Khrunichev's official data. In total, if amortization is achieved for 125 launches, the savings will decrease by $5.4 \%$.

Finally, the savings will be only $11.1 \%$. In comparison with the "ideal" case with $48.5 \%$ savings, the real case is by $37.4 \%$ worse. The savings for the launch vehicle of a lighter type will be lower and even may become negative.

The similar analysis can be done for other reusable technologies, but for the sake of brevity, only experts' opinion is presented herein.

As per evaluations of the American consulting company, Teal Group Corporation, at present, there are no commercial RLV and economically profitable projects of a similar type. It is worth to point out that more than tens RLV development programs were stopped due to high risk, stipulated by the use of new complicated technologies.

As to reusable stages with hypersonic parallel-flow jet engine (HPFJE), their first flight is expected to be not earlier than in 2015. According to the experts' opinion, such stages will never inject a large payload mass into the orbit and compete the systems with rocket engines. Most likely, a payload mass will be about $9 \mathrm{t}$ and the cost will be $\$ 4,250$ per $1 \mathrm{~kg}$ of payload (in comparison with $\$ 6,250$ per $1 \mathrm{~kg}$ for the initial ELV). More than $\$ 4,000$ million were spent for investigations of hypersonic propulsion within last 40 years in the USA.

Thus, even the most perspective projects do not allow one to expect the economically expedient RLV development (and the corresponding decrease in payload injection cost) in the nearest 15 years. Moreover, even beyond 15 years, it is hardly possible to expect the qualitative cost decrease for launches.

\subsection{Conceptual Ways of Couping with Problems}

The analysis of reentry systems, conducted by the authors, shows that all these systems have the common features. These features can be generalized by the following concept:

Onboard equipment of reentry system plays a main role, while the external equipment one plays, in general, an auxiliary role.

It is not a surprise that this concept covers not only a Fly-Back technology, but also all systems, which ensure a descent with parachutes and landing due to inflatable sacks or "soft" landing engines. 
For example, consider the K-1 launch vehicle project of "Kistler" company. Despite the parachute system used for descent and air sacks used for landing provide potentially a possibility to attain the smaller mass and cost for reentry stages in comparison with the Fly-Back technology, a need to solve a landing problem requires excessive onboard equipment and therefore special conditions for landing.

The stages are compelled to land on deserted territories with an appropriate relief near the launch pad. The partition of the stages and injection trajectory are therefore not optimal. Moreover, there is a necessity to send a return impulse to stages for the reentry to the launch point. As a result, additional equipment mass as well as manufacturing and service costs will increase, whereas the reliability will decrease. Clearly, all limitations and problems of the concept under discussion are readily looked through.

The above problems relate to all projects (without exclusion) which implement this concept and are independent of the way how reentry is realized (FlyBack technology, parachute and air sacks, or something else). So, the only method of cost decrease is a "direct" solution of the problems listed above, i.e., the development of qualitatively new technologies ensuring decreasing the mass of structure and devices, increasing reliability, and decreasing the costs of manufacturing and service.

One can readily realize that the above requirements are in a rigid inconsistency with each other. For example, for increasing reliability, it is necessary to rise the margins for loads, to implement duplications, to rise the requirements to manufacturing and monitoring, etc. As a result, a significant cost increase and booster mass increase can be expected. The same relates to other requirements.

According to the experience of working on reusable system projects, an attempt to break this "vicious circle" staying within the framework of the same concept fails. The appearance of new technologies capable of resolving this inconsistency can be expected not earlier than by 2015 .

Is there another concept, which was already used in practice and has allowed resolving a similar problem? Yes, it is! Remember a history of distant aircraft development. In 1954, there was a necessity of a nonstop flight on large distances. One of the solutions was to hope on the development of new technology which could qualitatively improve technical parameters of flights. However, even with current technologies, the distant aircraft is not available today. Another solution was found. The problem of flight at large distances was divided between carrier and tanker airplanes. As a result, a distant aircraft was developed using available technologies.

This experience can be generalized to the following concept with the reference to reentry systems:

Optimum separation of reentry problem is required between ground and onboard equipment (hereinafter is simple optimum separation). 


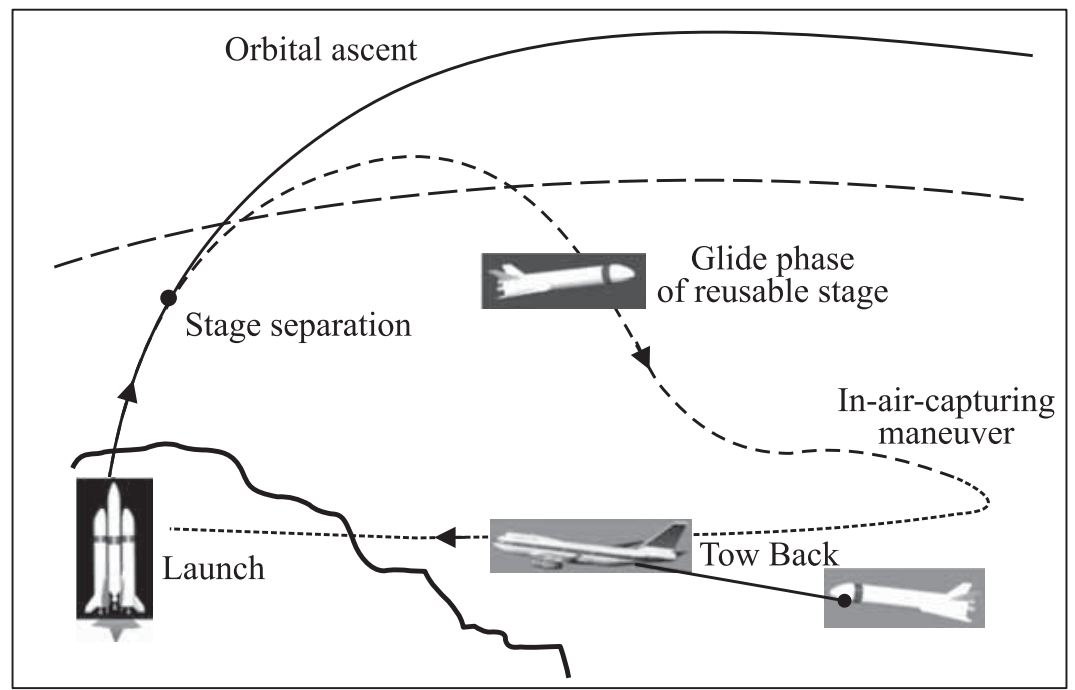

Figure 7 DLR-SART project

It is the authors' and their scientific chief's opinion that it is necessary to search for design solutions permitting the real decrease of payload injection cost just within the framework of this concept.

An example which can be related to this concept is the project of "Space Launcher Systems Analysis" (SART) by DLR of the German Space Agency (DLR-SART) [6]. It offers (Fig. 7) to capture the RB gliding in atmosphere (after separation from launch vehicle) by airplane and to tow it to the airdrome at the launching site. When approaching the airdrome, the booster separates and lands. It is seen from Fig. 7 that booster configuration is very similar to the configuration of boosters made by Fly-Back technology. However, it is not a Fly-Back technology, as the booster flies to the launching site not by itself. The approach is seen how to divide a reentry problem optimally between onboard and ground equipment (i.e., according to the concept offered by the authors). Due to this, the necessity of using additional jet engines with additional propellant and tanks is avoided. As a result, the increase of the payload mass to be injected into Geosynchronous Transfer Orbit (GTO) in comparison with the classical Fly-Back technology will attain $25 \%$ !

Note that this essential result is not connected with the use of composite materials or super advanced technologies. It is just a result of another conceptual approach.

However, the use of wings and chassis is not a good solution combined with the launch vehicle arrangements and problems. The wings and chassis are not 
used at injection and at reentry the wing brings to essential transversal loads. As a result, the increase in "dry" mass does not completely favors the optimal separation concept advantages. The savings are lower in the case of wing appliance and higher in the case of parachute appliance because in the last case, the mass and cost of all systems used for retrieval are lower.

\subsection{Economic Effectiveness of MAR Technologies}

The question arises: How one can solve the reentry problems due to the offered concept? To answer this question, consider the diagram in Fig. 8 which is similar to Fig. 6 discussed above. For the further analysis, the manufacturing costs are divided into the cost of the launch vehicle first stage (49\%), second stage (12.3\%), and remaining part (18.2\%). Now, when transforming this ELV to the reusable

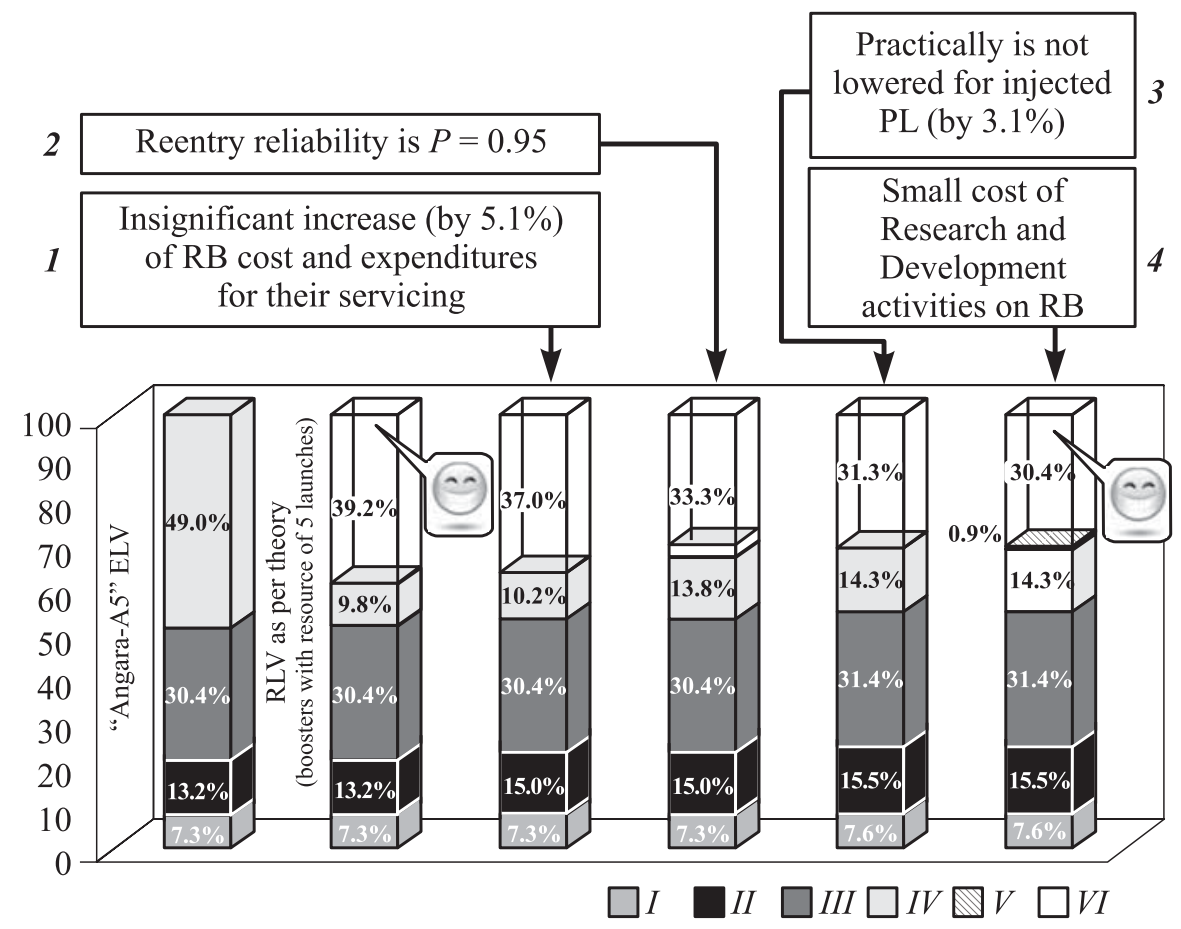

Figure 8 Advantages of offered technology of reentry on example of "Angara-A5" transformed launch vehicle: I - adaptation with PL; II - reusable part of launch vehicle; III - launch support; IV - amortization (125 launches); V - expendable part of launch vehicle; and VI — saving 
launch vehicle with multiply used boosters of the first stage, the technologies and technical solutions offered by the authors will be used as contrasted to Fig. 6. By taking successfully into account the influence of all solutions, one arrives at the conclusion that the use of the offered reentry technology leads to the economy of $30 \%$, i.e., only $8.8 \%$ less than that for an ideal case.

\section{CONCLUDING REMARKS}

Except for the MAR technology, other technologies postpone the development of the economically effective RLV to indefinite future. This practice exists for several decades. Various combinations of the same concepts are considered (e.g., the Fly-Back technology). However, all the attempts end with the claim for the necessity of new materials and technologies to prove the effectiveness of the design solutions.

Today, it is necessary to start working on the RLV based on the MAR technology. The MAR technology is based on the current technological capabilities and materials. The new technologies and materials, if they are invented, will help to improve the MAR technology and will make its application more profitable.

\section{REFERENCES}

1. Aviation Week. 1966. 11:33; 12:37.

2. Samos. 1963. Rech. Spatiale 2(10):25-26.

3. http://lenta.ru/world/2001/08/02/genesis/.

4. Jorgensen, D. S., R.A. Haggard, and G. J. Brown. 2005. The past, present, and future of mid-air retrieval. AIAA Paper No. 2005-1673.

5. Antonenko, S. V., S. A. Belavskiy, and A. A. Medvedev. 2002. Object capture methods. Patent No. RU 2242409 C2. Priority 21.08.02.

6. http://www.la.dlr.de/ra/sart/. 